\title{
PENDIDIKAN ISLAM BERBASIS IESAQ
}

Dikirim tanggal 27 September 2017 Diterima tanggal 26 Desember 2017 Dipublish tanggal 27 Desember 2017

\section{Mila Hasanah}

Fakultas Tarbiyah dan Keguruan Program Studi Pendidikan Guru

Madrasah Ibtidaiyah

UIN Antasari Banjarmasin

E-mail: milahasanah99@gmail.com

\begin{abstract}
The problematic of education is too oriented to cognitive aspect only, less attention to aspects of IESAQ. IESAQ-based Islamic education, offered in this article by literature research methods. IESAQ that integrates and integrates intellectual, emotional, spiritual and adversity Quotient development in the educational environment. Being able to enjoy the process toward success even though they know that there will be many obstacles and difficulties facing. However, behind the difficulties he will get a lot of convenience. Strategy Improving IESAQ: through experience of intellectual activity, experience of structured and fasting, safar, zikr, contemplation, zuhud and jihad. Or with the tathahhur strategy that is habitually obedient shari'ah, muhasabah, mujahadah and riyadhah al-nafs.
\end{abstract}

Key Word: Islamic Education, based on, IESAQ

\begin{abstract}
ABSTRAK
Problematika pendidikan diantaranya adalah terlalu berorientasi kepada aspek kognitif saja, kurang memperhatikan aspek IESAQ. Pendidikan Islam berbasis IESAQ, ditawarkan pada artikel ini dengan metode penelitian kepustakaan. IESAQ yang mengintegrasikan dan memadukan pengembangan aspek intelektual, emosional, spritual dan Adversity Quotient dilingkungan pendidikan. Mampu menikmati proses menuju keberhasilan walau mereka tahu bahwa akan banyak rintangan dan kesulitan yang menghadang. Namun, di balik kesulitan itu ia akan mendapatkan banyak kemudahan. Strategi Meningkatkan IESAQ: melalui pengalaman kegiatan intelektual, pengalaman terstruktur dan puasa, safar, zikr, kontemplasi, zuhud dan jihad. Atau dengan strategi tathahhur yaitu pembiasaan taat syari'at, muhasabah, mujahadah dan riyadhah al-nafs.
\end{abstract}

Kata Kunci: Pendidikan Islam, berbasis, IESAQ.

\section{PENDAHULUAN}

Orang-orang cerdas banyak sekali jasanya dalam kemajuan dan memajukan umat manusia. Melalui hasil karya dan pandanganpandangannya yang ilmiah, telah mampu membebaskan masyarakat dari kebodohan dan kebiadaban, menuju tatanan yang lebih baik dan beradab. Karya-karya orang cerdas pula, yang memungkinkan umat manusia mendapatkan fasilitas teknologi modern, dalam 
memberikan berbagai kemudahan (Jeanne Segal, 2001: 2).

Firman Allah SWT., dalam Surah Al-Baqarah, ayat 30:

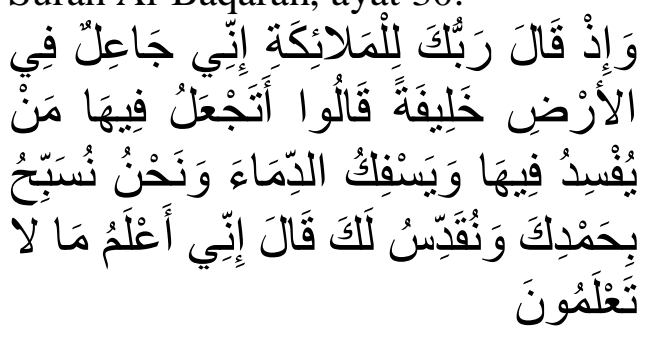

Ayat di atas menjelaskan bahwa setiap manusia dilahirkan berpotensi menjadi cerdas, karena secara fitri, manusia dibekali potensi kecerdasan oleh Allah SWT., dalam rangka mengaktualisasikan dirinya sebagai hamba (abid) dan wakil Allah (khalifatullah) di bumi (Suharsono, 2001: 13, Fu'ad Nashori (ed.), 1994: 117 dan Hasan Langgulung, 1988: 137).

Tapi disisi lain, dunia pendidikan saat ini mengalami problematika yang perlu segera ditangani, diantaranya adalah pendidikan terlalu berorientasi kepada aspek kognitif yang mengembangkan potensi kecerdasan intelektual (IQ) saja, kurang memperhatikan aspek kecerdasan emosional dan kecerdasan spritual apalagi kecerdasan bertahan dan mengatasi kesulitan (AQ). Karena pendidikan masih terpengaruh dengan paradigma kecerdasan intelektual ini, akibatnya dalam pendidikan, ukuran kecerdasan seseorang terarah kepada nilai matematika dan bahasa, kunci kesuksesan adalah nilai-IQ (rapor, indeks prestasi, dll.) dan berorientasi pada pemecahan masalah. Lebih parah lagi, dekadensi moral seakan terabaikan dan tak tersentuh oleh dunia pendidikan.
Pendidikan agama memang telah diwajibkan pada semua jenjang pendidikan sebagai mata pelajaran yang alokasi waktunya sangat kecil, dan dalam dataran implementasi terkesan bahwa tanggung jawab pembinaan agama dan akhlak anak hanya dipikul oleh guru agama. Menyadari kelemahan tersebut, sekarang ini sedang ramai didiskusikan berbagai alternatif untk mengatasi masalah tersebut.

Pendidikan Islam berbasis IESAQ, ditawarkan sebagai salah satu alternatif pemecahan masalah pendidikan dengan konsep pendidikan yang mengintegrasikan dan memadukan pengembangan aspek intelektual, emosional, spritual dan Adversity Quotient dilingkungan pendidikan. Oleh karena itu, artikel ini menggunakan metode penelitian kepustakaan membahas bagaimana IESAQ dalam perspektif Islam, strategi meningkatkan IESAQ, dan bagaimana konsep pendidikan Islam berbasis IESAQ.

\section{PEMBAHASAN}

\section{A. IESAQ dalam Perspektif} Islam

IESAQ adalah Intellegence, Emotional, Spritual and Adversity Qoutient. Pertama, kecerdasan intelektual atau IQ adalah singkatan dari Intelligence Quotient yaitu suatu kecerdasan yang dikaitkan dengan kemampuan struktur akal (rasio) menangkap gejala sesuatu, sehingga kecerdasan ini hanya bersentuhan dengan aspek-aspek kognitif, seperti kemampuan berpikir, daya menghubungkan, menilai, dan kemampuan memecahkan masalah dengan logika. (JP Chaplin, 1989: 253- 
254). Kecerdasan intelektual diartikan juga sebagai kemampuan intelektual, analisa, logika dan rasio. Ia merupakan kecerdasan untuk menerima, menyimpan dan mengolah infomasi menjadi fakta. Jadi, yang dimaksud IQ pada dasarnya adalah ukuran atau tarap kecerdasan intelektual seseorang yang ditentukan berdasarkan hasil test inteligensi. Baik itu berupa kemampuan seseorang dalam memainkan potensi logika, kemampuan berhitung, menganalisa dan matematika (logical mathematical intelligence).

IQ identik dengan العقل (al 'aql) yang mengandung arti mengikat atau menahan, tetapi secara umum akal difahami sebagai potensi yang disiapkan untuk menerima ilmu pengetahuan القوه المهنة لقبول العلم alquwwah al-mihnah liqabuli al'ilm). Dalam psikologi modern akal dipahami sebagai kecakapan memecahkan masalah (problem solving capacity). (Malinda Jo Levin, 1978: 110-112). Kata al 'aql dalam Al-Qur'an tidak pernah disebut dalam bentuk kata benda, tetapi selalu dalam bentuk kata kerja, baik kata kerja fi'il mady maupun fi'il mudhari'. Dalam al-Qur'an, kalimatal-aql disebut dalam 49 ayat, عatu kali dalam bentuk kalimat عقوله (uquulahu), 24 kali dalam bentuk kalimat تعقلون (ta'qiluuna) (Q.S. alBaqarah/2: 44, 73, 242 dan Q/3: 65, 118), satu kali نعقل (na'qilu), satu kali يعقلو ها (ya'qiluha) dan 22 kali dalam bentuk يعقلون (ya'qiluuna). Antara lain surat al-Baqarah/2:164, 170, 171, Q/5:58, 103, Q/8: 22, Q/10: 42, 100. Misalnya dalam surah alBaqarah, ayat 44:

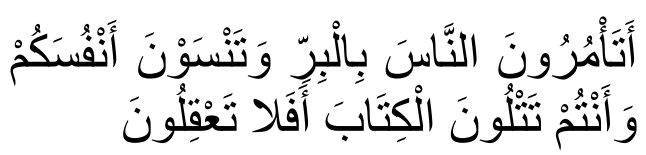

Dan Sabda Rasulullah SAW. (AnNasa'i, 1348 H: 459):

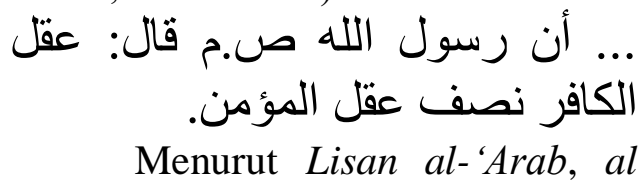
'aql juga berarti الحجر (al-hijr) yang artinya menahan, sehingga yang dimaksud dengan orang berakal, العاقل (al-'aaqil), adalah ذى حجر (dzi hijr), orang yang menahan diri dan mengekang hawa nafsu (Ibn Manzur, [tth]: 3046). Al-Qur'an juga menyebut orang berakal dengan beberapa istilah, seperti اولى النهى (uulin nuhaa) yang berarti orang yang memiliki pencegah atau akal yang mencegah dari keburukan, اول العلم)(uulul 'ilm), orang yang berilmu, اول الباب (ulul al-baab), orang yang mempunyai saripati akal, (misalnya surat al-Baqarah/2: 269, Q/3: 7, Q/13: 19, Q/14: 52, Q/38: 29 dan Q/39:9) اولوال الأبصار (ulul al-Absar) orang yang mempunyai pandangan tajam, dan (dzi hijr), orang yang mempunyai daya tahan.

Berdasarkan 49 ayat menyebut al 'aql, kata 'aql mengandung pengertian mengerti, memahami dan berpikir. Tetapi pengertian berfikir juga diungkapkan al-Qur'an dengan kata yang lain, seperti (nazhara) yang artinya melihat secara abstrak (Q/50:6-7, Q/86:5-7, Q/88:17-20), (tadabbara) yang artinya merenungkan (Q/38:29, Q/47:24), tafakkara yang artinya berfikir (Q/16:68-69, Q/45:12-13), faqiha yang artinya mengerti (Q/17:44, Q/16:9798, Q/9:12), tadzakkara yang artinya mengingat, memperoleh pengertian, mendapatkan pelajaran, 
memperhatikan dan mempelajari (Q/16:17, Q/39:9, Q/51:47-49), dan dalam kalimat fahima yang artinya memahami (Q/21:78-79) (Achmad Mubarak, 2001: 57 dan Abdul Munir Mulkhan, 1993: 175). Meskipun banyak istilah dalam al-Qur'an yang berhubungan dengan aktifitas akal, tetapi 'aqala mengandung arti yang pasti, yaitu mengerti, memahami dan berfikir. Jadi, pengertian IQ, yaitu kemampuan untuk mengerti, memahami dan berfikir (rasio) menangkap gejala sesuatu, daya menghubungkan, menilai, dan kemampuan memecahkan masalah dengan logika.

Kedua, EQ atau Emotional Quotient (Kecerdesan Emosi) adalah kemampuan pengendalian diri, nafsu dan emosi serta pengetahuan tentang diri sendiri. Mengetahui diri sendiri yang dimaksudkan disini bukanlah diri yang bersifat fisik, seperti tinggi badan, warna kulit dan sebagainya tetapi berkenaan dengan "fenomenafenomena kedirian". Mengetahui diri sendiri berarti mengetahui potensipotensi dan kemampuan yang dimiliki sendiri, mengetahui kelemahan-kelemahan dan juga perasaan dan emosi (Suharsono, op cit.: 108 dan Toto Tasmara, 2001: viii). Dengan mengetahui hal tersebut, seseorang mestinya juga bisa mendayagunakan, mengekspresikan, mengendalikan dan juga mengkomunikasikan dengan pihak lain.

Tetapi yang lebih mendalam lagi EQ adalah kemampuan untuk menemukan visi dan tujuan hidup, secara substansial. Jika manusia mampu menemukan visi hidupnya secara jelas, maka ia akan menjalani kehidupan itu dengan langkah- langkah yang pasti, terencana dengan baik dan tentunya dengan kesadaran yang luas. Orang seperti ini, tidak akan "membelokkan perjalanan" atau mengorbankan hidup dan masa depannya hanya karena keusilan orang-orang jahil atau karena hal-hal yang sepele.

Fungsi-fungsi psikologis dalam Al-Qur'an disebut dengan nafs/jiwa $\quad(\mathrm{Q} / 5: 32, \quad \mathrm{Q} / 36: 54$, $\mathrm{Q} / 13: 11), \quad$ qalb/hati $\quad(\mathrm{Q} / 22: 46$, Q/7:179) tapi Al-Qur'an menyebutkan juga fu'ad untuk menyebut hati manusia $(\mathrm{Q} / 17: 36)$ dan (Q/26:86), aql (akal), hawa (dorongan negatif syahwat). Nafs merupakan ruangan luas di dalam diri setiap manusia sebagai sistem nafsiah dengan sub sistem akal sebagai alat berfikir, qalb sebagai alat memahami yang sering tidak konsisten, bashirah sebagai mata batin yang konsisten (AlQiyamah:14-15), fitrah sebagai desain awal yang menetapkan fungsi (Q/30:30), syahwat sebagai motif penggerak, hawa nafsu sebagai motif menyimpang $(\mathrm{Q} / 4: 27)$, dan ruh sebagai spirit yang menyebabkan semuanya berfungsi (Q/17:85). (Achmad Mubarak, op cit.: 68).

Menurut al-Qur'an, struktur bashirah dalam sistem nafs dapat diilustrasikan sebagai berikut; manusia memiliki dimensi ruhani yang terdiri dari nafs, aql, qalb, ruh dan basirah. Nafs diibaratkan sebagai ruangan yang sangat luas dalam alam ruhani manusia. Dan dalam nafs itulah manusia digerakkan untuk menangkap fenomena yang dijumpai, menganalisanya dan mengambil keputusan. Kerja nafs dilakukan melalui jaringan qalb, aql dan 
bashirah, tetapi kesemuanya itu baru berfungsi manakala ruh berada dalam jasad dan fungsi kejiwaan telah sempurna. Firman Allah SWT., dalam surah Al-Hajj: 46:

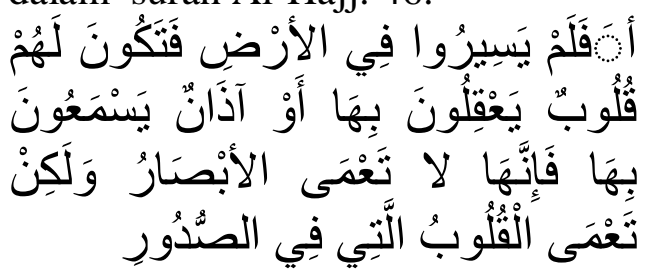

Dan Hadits Rasulullah SAW (Abu Dawud, [tth.]: 347):

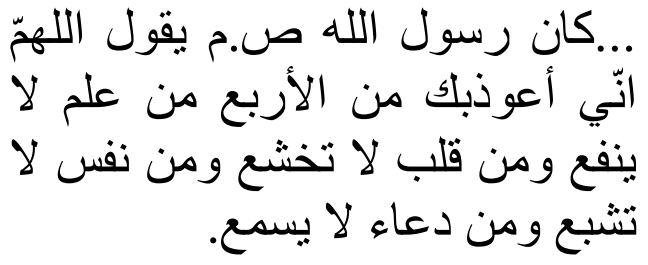

Juga pada hadits (Muslim, 1972: no. 2564 Sunan Ibnu Majah, 1404H: 1388):

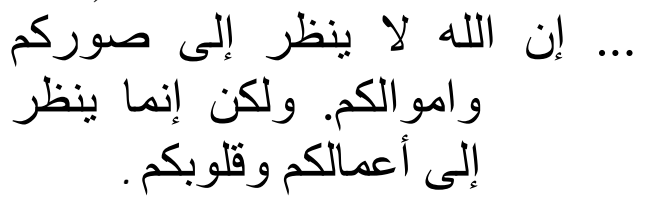

Qalb merupakan bagian dalam nafs yang bekerja memahami, mengolah, menampung realita sekelilingnya dan memutuskan sesuatu. Sesuatu dengan potensinya maka qalb merupakan kekuatan yang sangat dinamis, tetapi ia temperamental, fluktuatif, emosional dan pasang surut (Jalaluddin, 1998: 163). Untuk memecahkan masalahmasalah yang dihadapi, qalb bekerja dengan jaringan akal, tetapi kondisi qalb dan akal terkadang tidak optimal sehingga masih dimungkinkan terkontaminasi oleh pengaruh syahwat, atau oleh motif kepada hal-hal yang bersifat negatif, dan dalam keadaan demikian aql dan qalb dapat melakukan helah mental, yakni memandang sesuatu yang salah, dengan alasan-alasan yang dibuatnya, seakan-akan yang salah itu wajar. Bashirah bekerja mengoreksi penyimpangan yang dilakukan oleh qalb dan aql. Dan juga disebut bahwa kondisi qalb dan $a q l$ yang tingkat kesehatannya optimal (al-qalb as salim) itulah yang disebut hati nurani atau bashirah.Jadi, EQ adalah kemampunan qalb untuk memahami, mengolah, menampung realita sekelilingnya dan memutuskan sesuatu juga kemampuan pengendalian diri, nafsu dan emosi serta pengetahuan tentang diri sendiri.

Ketiga, SQ (Spiritual Qoutient) adalah Kecerdasan Spiritual, istilah spiritual berasal dari kata spirit, artinya: semangat, jiwa, sukma dan ruh. (Departemen Pendidikan Nasional, 2002: 1087). Pada umumnya tokoh-tokoh Barat Modern dewasa ini mendefinisikan 'spritual' bagi SQ, Zohar mengutip definisi dari Webster's Dictionary, 'spirit as the animating or vital principle; that gives life to the physical organism in contrast to its material elements; the breath of life' (Danah Zohar, 2000: 4). Bagi Zohar spiritualis tidak harus dikaitkan dengan kedekatan seseorang dengan aspek Ketuhanan, sebab menurutnya seorang humanis atau athies pun dapat memiliki spiritualitas yang tinggi.'..many humanits and atheist have high SQ, many actively and vociferously religious people have very low $S Q$ (Danah Zohar, 2000: 9).

Ini berbeda dengan pandangan Islam, kata spirit yang dalam bahasa Arabnya ruh, dan spiritual (ruhiyyah), tidak pernah 
dilepaskan dengan aspek Ketuhanan. Al-Qur'an mengatakan: "mereka bertanya kepadamu tentang ruh, katakanlah: Ruh itu 'amr Rabbi (amr Tuhanku)." Seperti firman Allah SWT seperti dalam surah Al-Isra' ayat 85:

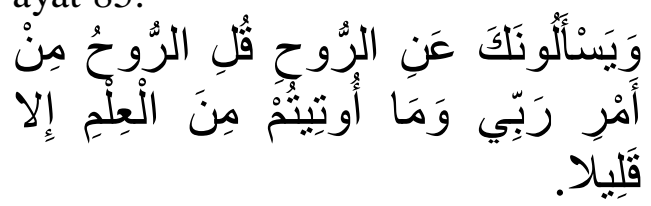

Sementara menurut danah Zohar menganggap bahwa spiritual itu adalah berupa God Spot atau Titik Tuhan. Al-Gazali mempergunakan terminologi al-qalb untuk pengertian emosi dan al-ruh untuk pengertian spiritual, seperti hadits Rasulullah SAW:

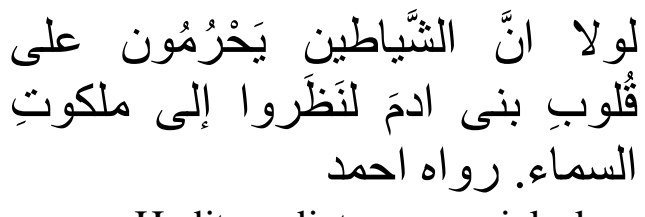

Hadits diatas menjelaskan hati yang bersih (terbebas dari pengaruh setan) dan telah diisi dengan dzikir serta keikhlasan kepada Allah akan dapat melihat "kerajaan langit". Dengan hati yang bersih manusia akan memperoleh ilmu dan hikmah (Al-Gazali, [t.th]: 8). Manusia yang memperoleh ilmu dan hikmah itulah manusia yang memiliki SQ yang tinggi karena darinya akan terpancar kebaikan yang banyak (Abdul Mujib dan Jusuf Mudzakir, 2001: 324-325).

Kecerdasan spiritual adalah sumber yang mengilhami, menyemangati dan mengikat diri seseorang kepada nilai-nilai kebenaran tanpa batas waktu. Kecerdasan spiritual cenderung diperlukan bagi setiap hamba Tuhan untuk dapat berhubungan dengan Tuhannya. Melibatkan kemampuan, menghidupkan kebenaran yang paling dalam, artinya mewujudkan hal yang terbaik, untuk dan paling manusiawi dalam batin. Gagasan, energi, nilai, visi, dorongan, dan arah panggilan hidup, mengalir dari dalam dari suatu keadaan kesadaran yang hidup bersama cinta.

Ruh menurut Al-Gazali mempunyai dua makna, yaitu makna fisik dan metafisik. Makna ruh secara fisik (jasmaniah) ialah energi kehidupan, sedangkan makna yang metafisik ialah sesuatu yang halus dari jiwa (hati) manusia (al-lathifat al-rabbaniyyah), yang mengerti dan mengetahui, ia adalah dimensi rohaniah manusia (Mubin, 2004: 149). Apabila pengertian ruh yang metafisik ini masuk kedalam hati maka muncullah pengertian dimensi hati yang rohani yaitu sesuatu yang halus/lembut, luhur dan bersifat ketuhanan. Dengan demikian, hakikat spiritual adalah sesuatu yang metafisik, bisa sesuatu yang berkaitan dengan roh yang luhur atau berdeminsi rohaniah dari hati manusia (hati nurani) yang mengandung sifat Ketuhanan. Itulah yang disebut fitrah, yang selalu menarik jiwa kepada keluhuran.

SQ merupakan kecerdasan yang tertinggi dalam struktur kepribadian manusia, maka berarti SQ terletak di atas atau lebih tinggi derajatnya daripada EQ. Tetapi, SQ baru akan dapat dikembangkan atau diperoleh setelah melalui tahapan EQ. Tahap ini di sebut zero mind process (Proses Penjernihan Emosi). SQ terletak pada wilayah paling dalam dari hati (lubb), tempat berlabuh getaran kebenaran dari Tuhan. Melalui dzawq (rasa ketuhanan) dan ruh, SQ mempunyai 
garis hubung terdekat menuju Tuhan, karena memang paradigma SQ adalah penghayatan, pengrasaan dan kesadaran ketuhanan guna mendapatkan pencerahan Ilahiyah (enlightenment) dalam nilai atau makna kehidupan yang universal dan transendental. Nilai atau makna kehidupan yang universal itu adalah kebenaran, keadilan dan kebaikan (Agus Nggermanto, 2002: 126-128). Sedangkan nilai transendental Ilahiyah, adalah merupakan cinta dan kasih sayang, serta damai bersama ridha Allah (M. Utsman Najati, 2003: 99). SQ merupakan puncak kepribadian manusia paripurna yang dalam tasawuf versi al-Gazali disebut al-'arifin (orang yang telah menerima pengetahuan kebenaran atau ma'rifah dari Allah melalui hatinya yang bersinar dan mata hatinya yang tajam) (M. Zurkani Jahja, 1997: 20).

SQ dalam konsep Barat sangat berbeda dengan konsep Islam. Dalam pandangan Islam sangat mustahil seseorang yang mengingkari keberadaan Tuhan (athies) mampu memiliki spiritualitas yang tinggi, kecuali bila makna 'spiritual' ang dimaksudkan bukan seperti makna ruhaniyyah dalam terminologi Islam. Maka dapat disimpulkan SQ dalam perspektif Islam adalah kemampuan ruh dalam menghayati, merasakan dan menyadari akan eksistensi Tuhan guna mendapatkan pencerahan Ilahiyah dalam nilai atau makna kehidupan yang universal dan transendental.

Keempat, AQ (Adversity Quotient), yaitu kecerdasan untuk mengatasi kesulitan. AQ merupakan faktor yang menentukan bagaimana, jadi atau tidaknya, serta sejauh mana sikap, kemampuan kinerja terwujud di dunia, dengan kata lain, orang yang memiliki AQ tinggi akan lebih mampu mewujudkan cita-citanya dibandingkan orang yang AQ-nya lebih rendah.

Sebagai gambaran, Stoltz meminjam terminology pendaki gunung, dia membagi menjadi tiga bagian, yaitu: 1. Quitter (yang menyerah); Tipe ini adalah orang bekerja sekedar untuk bertahan hidup. Mereka ini gampang putus asa dan menyerah di tengah jalan. 2 . Camper (berkemah di tengah perjalanan); Tipe yang satu lebih baik, karena biasanya mereka berani melakukan pekerjaan yang berisiko, tetapi tetap mengambil risiko yang terukur dan aman. "Ngapain capekcapek" atau "segini juga sudah cukup" adalah motto para campers. Orang-orang ini sekurang-kurangnya sudah merasakan tantangan dan selangkah lebih maju dari para quitters. Sayangnya banyak potensi diri yang tidak teraktualisasikan, dan yang jelas pendakian itu sebenarnya belum selesai. 3. Climber (pendaki yang mencapai puncak). Orangorang dengan golongan ini adalah mereka yang dengan segala keberaniannya menghadapi risiko akan menuntaskan pekerjaannya. Mereka mampu menikmati proses menuju keberhasilan walau mereka tahu bahwa akan banyak rintangan dan kesulitan yang menghadang. Namun, di balik kesulitan itu ia akan mendapatkan banyak kemudahan (Aswandi, 2012). Sesuai dengan firman Allah SWT: "Karena sesungguhnya sesudah kesulitan itu ada kemudahan" (QS Al-Insyirah/98 :6). 
Ada beberapa faktor yang mempengaruhi pembentukan atau perkembangan IESAQ seseorang, yaitu: pembawaan, kematangan, pembentukan, minat dan kebebasan (M. Alisuf Sabri, op cit: : 123-125 dan M. Ngalim Purwanto, 2000: 56). Individu yang memiliki IESAQ yang baik dan terstandar maka akan memiliki kemantapan pemahaman tentang potensi diri dan pengembangannya untuk kegiatankegiatan yang kreatif dan produktif dalam kehidupan sehari-hari maupun untuk peranannya sebagai pelaksana/pelaku profesi.

IESAQ tidaklah berkembang secara alamiah, artinya seseorang tidak dengan sendirinya memiliki kematangan IESAQ semata-mata didasarkan pada perkembangan usia biologisnya. Sebaliknya IESAQ sangat tergantung pada proses pelatihan dan pendidikan yang kontinu. Kecerdasan IESAQ bawaan bisa berkembang atau rusak, hal ini tergantung pada pengaruh yang diperoleh anak di masa kecil atau remaja (Mila Hasanah, 2007: 68). Pengaruh ini bisa datang dari orang tua, keluarga atau sekolah. Anak melalui hidupnya dengan potensi yang baik untuk perkembangan IESAQ, tapi pengalaman yang dialaminya di lingkungan anarkhis atau tidak bersahabat menyebabkan grafik perkembangan IESAQ-nya menurun. Sebaliknya, bisa saja seorang anak mempunyai IESAQ bawaan yang rendah, tapi dididik dengan baik melalui pengalamanpengalaman yang ramah dan bersahabat. Perkembangan IESAQ yang diperlihatkan lingkungnya menyebabkan grafik IESAQ-nya menjadi tinggi. Perlu kita ingatkan disini bahwa merusak IESAQ anak adalah lebih mudah dari pada mengembangankannya karena menghancurkannya selamanya lebih mudah dari pada membangun. Jadi, perkembangan IESAQ dipengaruhi oleh faktor bawaan, kematangan, pembentukan, minat dan kebebasan juga dipengaruhi proses pelatihan dan pendidikan yang kontinu.

\section{B. Strategi Meningkatkan} IESAQ

Kualitas IESAQ bisa ditingkatkan melalui pengalaman kegiatan seperti meneliti fenomena alam semesta, akan terjadi proses dan akselerasi (percepatan) berfikir, pengingat dan juga perluasan wawasan. Proses itu terjadi, karena dalam semesta terdapat hukumhukum (sunnatullah) yang tetap, yang dapat dipelajari, dinalar dan akhirnya diambil hikmah dan manfaat. Seperti diisyaratkan dalam surat al-Jasiyah, ayat 3-5.

Selain itu pengalaman berstruktur dapat meningkatkan IESAQ, seperti berusaha memilah-milah dan menangkap pesan al-Qur'an. Hal ini diisyaratkan surat az-Zkhruf, ayat 3 dan surat Fussilat ayat 3-4. Juga penggunaan panca indera secara optimal dapat membantu meningkatkan kecerdasan intelektual, seperti diisyaratkan surat al-Anfal ayat 22.

Hal umum yang sudah diketahui adalah dengan melakukan ibadah puasa maka kemampuan otak yang bersifat matematis-linguistik akan meningkat, dikarenakan darah akan lebih banyak mengalir ke otak dibandingkan dengan tidak puasa. Dalam keadaan tidak puasa, darah akan dipompa oleh jantung sebesar $15 \%$ dari seluruh sirkulasi darah. 
Dengan peningkatan aliran darah lebih dari $15 \%$ maka otak akan lebih mampu berkonsentrasi.

Ada lima strategi untuk meningkatkan IESAQ, yaitu: mengenal emosi diri sendiri, mengelola emosi, memotivasi diri, mengenal emosi orang lain, dan membina hubungan. Konsep tazkiyat al-Nafs, ada tiga tahap/proses: tahap tahaqquq (realisasi), tahap takhalluq (perubahan perilaku) (Sa'id Hawwa, 2002: 2). Tahap tathahhur dapat dikategorikan sebagai strategi yang menitik beratkan pada proses psikoedukasi, sedangkan tahap tahaqquq dan takhalluq merupakan strategi psiko-spiritual. Untuk proses tathahhur, terbagi pada tiga tahapan, yaitu: strategi pembiasaan taat syari'at, muhasabah, dan mujahadah dan riyadhah al-nafs (Mubin, 2005: 90).

Orang tua adalah seseorang yang pertama kali harus mengajarkan IESAQ kepada anak dengan memberikan teladan dan contoh yang baik. Agar anak memiliki IESAQ yang tinggi, orang tua harus mengajarkan anaknya untuk: membina hubungan persahabatan yang hangat dan harmonis, bekerja dalam kelompok secara harmonis, berbicara dan mendengarkan secara efektif, mencapai prestasi yang lebih tinggi sesuai aturan yang ada (sportif), mengatasi masalah dengan teman yang nakal, berempati pada sesama, memecahkan masalah, mengatasi konflik, membangkitkan rasa humor (Rea-Bradley, 1999: 6063), memotivasi diri bila menghadapi saat-saat yang sulit, menghadapi situasi yang sulit dengan percaya diri dan menjalin keakraban.
IESAQ dapat diasah kualitasnya melalui pengalaman hidup, muhasabah (kalkulasi diri), mujahadah (latihan sprituil). Safar (perjalanan), zikr, kontemplasi (perenungan), saum (puasa), zuhud dan jihad, kesemuanya itu dapat menajamkan kekuatan IESAQ. Semangat hidup orang yang memiliki IESAQ lebih kontruktif dibanding semangat hidup rasionil. Jika seseorang sudah terlatih dalam mengelola IESAQ, maka ia dapat meningkatkan kehidupan ketingkat yang lebih tinggi.

Sebaiknya IESAQ distimulus agar memperoleh kecerdasan yang maksimal dimulai sejak prenatal (Susan Ludington-Hoe\&Susan K. Golant, 2001: 12-31). Apabila ibu yang sedang hamil mampu menjaga dimensi-dimensi IESAQ dan sekaligus kesehatan fisikal dan gizi dengan baik, maka Insya Allah, ia telah mempersiapkan diri bagi lahirnya anak yang cerdas.

$$
\text { Meningkatkan }
$$

kualitas

IESAQ , berdasarkan firman Allah SWT., dalam surah al-Isra: 75, alHajj: 46, an-Nur: 35 dan surah Ali Imran: 190-191. Juga hadits Rasululullah SAW, (Al-Bukhari, Shahih Bukhari, 1971: 134 dan Jalaluddin Abdurrahman ibnu Abi Bakar As-Suyuthi, [tth]: 94), diantaranya:

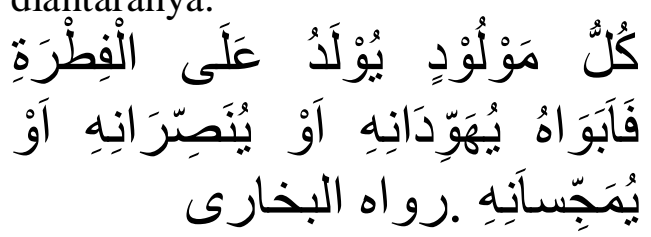

Secara konkret, ada delapan strategi yang harus dilakukan secara individu untk menjadi meningkatkan IESAQ, yaitu: 1. mengenal motif yang paling dalam (Knowing our 
deepest motives), 2. kesadaran diri yang tinggi (A High Degree of SelfAwareness), 3. tanggap terhadap diri yang terdalam (Responsive to the Deep Self), 4. kemampuan untuk memanfaatkan dan mengatasi kesulitan (A Capacity to Use and Transcend Difficulties), 5. kemapuan berdiri menentang orang banyak (Standing against the crowd), 6. keengganan untuk menyebabkan kerusakan (Reluctance to cause harm), 7. menjadi cerdas secara spiritual dalam agama (Being Spiritually Intelligent about Religion), 8. menjadi cerdas secara spiritual mengenai kematian (Being Spiritually about Death) (Zohar-Ian Marshall, 2000: 70). Selain itu meningkatkan IESAQ dapat melalui: membaca kitab suci, pelajari kehidupan para nabi dan orang saleh, belajar dari orang ber-IESAQ tinggi, biasakan mengubah "di dalam diri" bukan "di luar diri", lakukan ibadat dengan serius, sediakan waktu khusus untuk berdoa, dan belajar menajamkan "indra batiniah".

Selain itu, strategi meningkat IESAQ, yaitu: Pertama, Mission Statement/ penetapan misi, yaitu syahadat: meliputi kekuatan sebuah misi (Q.S. Faathir/35:5), membangun misi kehidupan (Q.S Ali Imran/3:9), membulatkan tekad (Q.S. Fushilat/41:30), membangun misi (QS. Al-An'am: 135), menciptakan wawasan (Q.S. Al-Insyiqaq: 6), transformasi visi (Q.S. Al-Ahzab, 21), komitmen total (Q.S. Ali Imran/3:18). Kedua; character Building/membangun karakter, yaitu Sholat: relaksasi (Q.S. Al-Ma'un:4-7), membangun kekuatan afirmasi (Q.S.Thaha: 50), Meningkatkan ESQ (Q.S. Thaha: 7), membangun pengalaman positif (Q.S. An-Nisa: 103), Pembangkit dan penyeimbang energi bathiniah (Q.S. Al-Baqarah: 238), Pengasahan Prinsip. Ketiga; Self Controlling/Pengendalian diri, yaitu puasa, meliputi: meraih kemerdekaan sejati, memelihara godspot, mengendalikan suasana hati, meningkatkan kecakapan emosi secara fisiologis (Q.S. Al-Baqarah: 183), pengendalian prinsip dan memelihara tata surya jiwa (Q.S. AlAnbiya: 33), Keempat; Strategi Collaboration, Kelima; Total Action/aplikasi total (Q.S. AlBaqarah:197): (Ary Ginanjar Agustian, 2001: 175-205). Jadi, ada berbagai strategi yang ditawarkan para pakar dibidangnya masingmasing, dalam mengembangkan pendidikan berbasis IESAQ sesuai dengan Al-Qur'an dan Hadits.

Agar IESAQ dapat bekerja optimal, maka "fuad" harus sesering mungkin diaktifkan (Ari Ginanjar, 2002: xliii). Manusia dipanggil untuk setiap saat berkomunikasi dengan fuad-nya, untuk melakukan atau tidak melakukan sesuatu, tanya dulu pendapat fuad/dhamir. Dengan cara demikian maka daya kerja IESAQ akan optimal, sehingga dapat memandu pola hidup seseorang. Inilah yang dimaksud oleh Rasulullah SAW dengan sabda beliau "sal dhamiruka" (tanya hati nurani). Fuad ibarat battery, yang kalau jarang dipakai maka daya kerjanya akan lemah, malah mungkin tidak dapat bekerja sama sekali. Dalam kaitan inilah agama menyeru manusia untuk mengagungkan Allah, membersihkan pakaian dan meninggalkan perbuatan dosa, separti dalam surah al-Mudatstsir, 74:1-5. Semua itu diperintahkan 
dalam kerangka optimalisasi daya kerja fuad/mempertinggi IESAQ seseorang. Perpaduan antara IESAQ akan membina jiwa secara utuh, sehingga seseorang dapat meniti karir dengan baik. Seseorang yang mampu mendayagunakan IESAQ itu secara seimbang kemungkinan besar akan mampu menggapai kehidupan yang damai dan bahagia baik di dunia maupun di akhirat.

IESAQ merupakan faktor yang menentukan bagaimana, jadi atau tidaknya, serta sejauh mana sikap, kemampuan kinerja terwujud di dunia, dengan kata lain, orang yang memiliki IESAQtinggi akan lebih mampu mewujudkan citacitanya dibandingkan orang yang IESAQ-nya lebih rendah. Orang yang memiliki IESAQ yang tinggi, adalah orang mampu menghadapi tekanan (tolerance to stress). Sikap percaya diri yang dilandaskan pada iman menyebabkan segala bentuk tekanan tidak dijadikan sebagai kendala, tetapi sebuah tantangan yang akan membentuk kepribadian menjadi lebih cemerlang. Justru mereka senang bekerja dibawah tekanan (working under pressure) yang akan menimbulkan kreativitas, dinamika, dan nilai tambah bagi dirinya (Toto Tasmara, op cit.: 229). Sebagaimana firman Allah SWT: "Janganlah kamu bersikap lemah dan bersedih hati, padahal kamulah orang-orang yang paling tinggi derajatnya jika kamu orang-orang yang beriman" (Q.S Ali Imran/3: 139). IESAQ melahirkan keyakinan, kekuatan dan kesungguhan untuk melahirkan hasil unjuk kerja yang bernilai tinggi (outstanding performance). Tidak mudah menyerah, tidak mudah patah, walaupun tantangan atau tekanan menghadang setiap langkah pekerjaannya, karena orang yang IESAQ-nya tinggi sangat yakin, bahwa nilai sebuah pekerjaan akan terasa semakin bermakna bila mereka mampu mengatasi setiap tantangan atau kendala yang dihadapi.

Al-Qur'an mengisyaratkan adanya tolak ukur kecerdasan, seperti yang tersebut dalam ayat al-Qur'an, dengan kriteria-kriteria sebagai berikut:

Pertama; mampu memahami hukum kausalitas,dalam Q/23:80, dari ayat tersebut disyaratkan bahwa dibalik kehidupan dan kematian ada faktor-faktor yang menyebabkannya. Demikian juga dibalik fenomena pergantian malam dengan siang ada sistem-sistem yang mengendalikannya. Orang yang tidak mampu memahami fenomenafenomena yang dapat disebut sebagai hukum sebab akibat adalah termasuk yang kurang IQ-nya.

Kedua; mampu memahami adanya sistem jagad raya, Q/26:1868, dialog panjang antara Nabi Musa dengan Fir'aun yang dikisahkan dalam surat as-Syu'ara Q/26:18-68, menggambarkan ketidakmampuan akal Fir'aun memahami fenomena jagat raya di mana dibalik itu pasti ada Sang Pengatur Yang Maha Mengetahui dan Maha Kuasa. Dalam hal ini Fir'aun dipandang tidak cerdas karena ufuknya sempit sehingga ia merasa dirinya sebagai Tuhan. Fir'aun tidak mampu memahami pernyataan Musa yang mengatakan bahwa Tuhan yang sebenarnya adalah yang menguasai seluruh alam semesta (Mila Hasanah, op cit: 64). 
Ketiga; mampu berfikir distinkip, Q/13:4, yaitu mampu memilah-milah permasalahan dan menyusun sistematika dari fenomena yang diketahui.

Keempat. mampu menyusun argumen yang logis, hal ini diisyaratkan surat Ali Imran, Q/3:6568 , yang berisikan teguran kepada kaum ahli kitab yang saling berbantah tanpa argumen yang logis.

Kelima; mampu berpikir kritis, terhadap pendapat dan gagasan yang disampaikan orang lain yang tidak mempunyai pijakan kebenaran. Surah Al-Maidah Q/5:103, misalnya menyebut tradisi jahiliyah yang menetapkan aturan berupa perlakuan tertentu yang harus dilakukan terhadap binatang ternak unta dan domba tertentu. Mematuhi tradisi yang tidak mempunyai pijakan kebenaran itu dipandang AlQur'an sebagai perbuatan bodoh.

Keenam; mampu mengatur taktik dan strategi perjuangan sehingga tidak terjebak pada strategi lawan. Hal ini diisyaratkan dalam surah Ali Imran Q/3:118-120, dalam ayat ini kaum mu'minin diingatkan Tuhan agar tidak mempercayai tugas-tugas strategis kepada orangorang yang mempunyai indikasi memusuhi Islam.

Ketujuh; mampu mengambil pelajaran dari pengalaman, (Achamd Mubarok, [t.th]: 64) Q/5:164-169. Menegur kaum Yahudi yang tidak bisa mengambil pelajaran dari sejarah yang mereka lalui. Ayat ini diakhiri dengan pertanyaan apakah kamu tidak mengerti.

Ciri-ciri seseorang memiliki IESAQ ialah: Empati (memahami orang lain secara mendalam), mengungkapkan dan memahami perasaan, mengendalikan amarah, kemandirian, kemampuan menyesuaikan diri, disukai, kemampuan memecahkan masalah, kesetiakawanan, keramahan dan sikap hormat. Sedangkan kunci kecerdasan IESAQ adalah kesabaran (Patricia Patton, 2000: 13). Sedangkan menurut Goleman, IESAQ yang tinggi yaitu: mampu memotivasi diri sendiri, bertahan dalam menghadapi frustasi, mengendalikan dorongan hati, tidak melebih-lebihkan kesenangan, mampu mengatur suasana hati, menjaga agar beban stress tidak melumpuhkan berpikir, berempati dan berdo'a (Daniel Goleman, 1999: 45). IESAQ melahirkan manusia yang memiliki akhlak mahmudah dan keterampilan berkomunikasi.

Orang yang memiliki IESAQ yang tinggi adalah orang yang hatinya dikuasai oleh sifat rabbaniyah, yaitu suatu keadaan hati yang telah mampu menaklukkan sifat-sifat saba'iyyah (kebuasan), bahimiyyah (kebinatangan), dan syaithaniyyah (godaan setan) (AlGhazali, [tth]: 10). Artinya ia telah dapat mengendalikan dorongandorongan nafsu atau egonya, sehingga emosi menjadi cerdas, segala sifat dan tingkah lakunya menunjukkan tanda-tanda ketinggian budi pekerti, dengan ciri sebagai berikut: 1. Mampu mengendalikan dorongan nafsu (qana'ah, zuhd, wara'). 2. Mampu memotivasi diri sendiri (al-niyyah, al-mujahadah, alikhlas). 3. Mampu bertahan dalam menghadapi cobaan (al-shabr, alistiqamah). 4. Tidak melebihlebihkan kesenangan (al-sukr, altawadhu). 
5. Mampu mengatur suasana hati (muthmainnah, al-'afwu, al-shidq). 6 Menjaga agar beban stres tidak melumpuhkan kemampuan berpikir (al-ridha). 7. Berempati dan berdo'a (kasih sayang, suka menolong sesama, dermawan dan memohon pertolongan kepada Allah) (Suriansyah Salati, 2009: 26). Sebenarnya

IESAQ

kecerdasan yang saling berkaitan dan dapat mempengaruhi keberhasilan seseorang, IESAQ diperlukan dalam mewujudkan seseorang yang pandai, kreatif, dapat berempati, dapat mengontrol emosi, serta memotivasi diri untuk mandiri, dan selalu mawas diri karena mengetahui perasaan yang ada didalam dirinya sendiri maupun orang lain. Dengan IESAQ dapat membantu memahami dan menghadapi dunia, diri sendiri dan orang lain. IESAQ adalah dua bagian dari satu keseluruhan, sumber sinergis: tanpa yang lain, menjadi tidak lengkap dan tidak efektif (Jeanne Segal, op cit.: 2 dan 5).

Ilmu yang tinggi adalah ibarat suatu senjata tajam, ia akan menjadi efektif bila digunakan oleh orang yang tepat dan tidak disalahgunakan. Dapat pula dikemukakan bahwa ilmu yang tinggi ibaratnya seperti kuda liar, sedangkan IESAQ adalah penunggang kudanya. Sangat baik jika kudanya sehat dan juga penunggangnya sehat, tetapi jika harus memilih, maka penunggang kuda yang sehatlah yang mengantarkan perjalanan itu sampai tujuan. Itulah maka IESAQ lebih menentukan dalam meraih kesuksesan hidup manusia (Ary Ginanjar Agustian, 2001: xxxviii).
Aspek/ranah IESAQ dalam Islam meliputi: Tobat (At-Tawbah, Sabar (al-Shabr), Syukur (al-syukr), Harap (al-raja), Takut (al-khawf), Zuhud (al-zuhd), Tawakal (altawakkal), Cinta (al-mahabbah) (Mubin, 2004: 150). IESAQ tinggi adalah: Kemampuan bersikap fleksibel, tingkat kesadaran diri yang tinggi, kemampuan untuk menghadapi dan memanfaatkan penderitaan, kemampuan untuk menghadapi dan melampaui rasa sakit, kualitas hidup diilhami oleh visi dan nilai-nilai, keengganan untuk menimbulkan kerugian yang tidak perlu, kecenderungan untuk melihat keterkaitan antara berbagai hal (holistik), dan kecenderungan untuk bertanya "mengapa" atau "bagaimana jika", dan berusaha mencari jawaban yang mendasar, serta menjadi teguh dalam pendirian (keyakinan) (Zohar-Ian Marshall, 2000: 65).

$$
\text { Adapun ciri-ciri IESAQ }
$$
tinggi: Pertama; Memiliki prinsip dan visi yang kuat, yaitu prinsip kebenaran, prinsip keadilan, prinsip kebaikan. Kedua; Visi yang kuat, Ketiga; Mampu melihat kesatuan dalam keanekaragaman, Keempat; Mampu memaknai setiap sisi kehidupan, Mampu bertahan dalam kesulitan dan penderitaan. Sejarah telah membuktikan, semua orang besar atau orang sukses telah melewati liku-liku dan ujian yang besar juga.

\section{Pendidikan Islam Berbasis IESAQ}

Pendidikan berbasis IESAQ berupaya menjawab berbagai problema pendidikan dewasa ini. Pendidikan berbasis IESAQ adalah sebuah konsep pendidikan integratif 
yang tidak hanya bertumpu pada pengembangan kompetisi kognitif peserta didik semata, tetapi juga pada penanaman nilai etika, moral, dan spritual. Oleh karena itu, demi mewujudkannya, dibutuhkan perencanaan matang dan berjangka panjang. Setidaknya, ada tiga langkah awal yang dapat ditempuh:

1. Rekonstruksi Kurikulum menjadi Kurikulum Holistik

Perlu upaya serentak, konstruktif, dan menyeluruh untuk merekonstruksi kurikulum melalui hal-hal sebagai berikut: Pertama; Sosialisasi kurikulum yang maksimal dan menyeluruh melalui berbagai pelatihan agar guru dan sekolah "siap" menjabarkan kurikulum secara kreatif. Kedua; Penambahan jam pembelajaran pada materi yang mendukung pendidikan berbasis IESAQ seperti PPKn dan pelajaran agama dengan mengurangi proses pembelajaran teoritis (Mubin, 2010: 6). Ketiga: Sistem evaluasi akhir yang berbasis kompetensi IESAQ. Evaluasi hendaknya tidak sebatas ujian tertulis semata, akan tetapi, perilaku dan etika keseharian seharusnya menjadi tolak ukur lulustidak lulusnya seorang peserta didik. Untuk itu, model Ujian Nasional perlu ditinjau ulang, sehingga alumni pendidikan tidak hanya berkompetensi dalam intelektualitas saja, tetapi juga kualitas karakter diri yang meliputi nilai moral dan spritual. Selain UN, evaluasi belajar lainnya seperti tes semester, ulangan harian, tidak ditekankan pada penilaian hasil jawaban di atas kertas saja, melainkan juga pada sikap peserta didik selama proses pembelajaran seperti tingkat absensi di kelas, mental anti-menyontek selama ujian, dan sikap moralspritual lainnya.

2. Optimalisasi Nilai IESAQ dalam Komunitas Pendidikan

Optimalisasi nilai-nilai

IESAQ ke dalam budaya edukatif sangat urgen untuk mengatasi ketimpangan antara kualitas kognisi dengan aspek non-kognisi yang selama ini masih berlaku dalam sistem pembelajaran. Pembentukan budaya tersebut tentu harus dilakukan secara bersama-sama oleh semua unsur yang berada dalam komunitas edukatif, meliputi pendidik (guru, kepala sekolah, dosen, maupun tenaga pengajar lainnya), komite sekolah, peserta didik, dan staf/karyawan biasa. Beberapa agenda awal yang bisa dibentuk sebagai sebuah budaya dalam komunitas edukatif, diantaranya: Pertama; Mengintegrasikan pendidikan IESAQ ke semua materi pembelajaran termasuk pelajaran sains, sehingga tidak berpusat pada aspek kognitif saja. Kedua; Perubahan paradigma "Siswa Teladan" dan "Bintang Pelajar". Jika selama ini pemilihan siswa teladan berangkat pada penilaian cognitivebased competition semata, sudah saatnya paradigma itu dihapuskan. Siswa teladan bukan saja siswa yang berprestasi dalam hal "juara kelas" dan semisalnya, akan tetapi, siswa yang berkarakter mandiri, taqwa, peka sosial, seharusnya mendapat apresiasi dan penilaian lebih. Ketiga; Pembenahan lingkungan belajar. Lingkungan yang sehat bukan saja memberikan stimulasi positif bagi proses transfer pengetahuan, tetapi juga memudahkan optimalisasi nilainilai luhur dalam lingkup 
pendidikan.

Keempat;

Mengembalikan fungsi fasilitas ibadah di lingkup akademik. Mushalla sekolah misalnya, dihidupkan kembali dengan budaya shalat berjamaah oleh segenap masyarakat sekolah, sehingga pelajaran agama tidak sekedar bernilai teoritis. Kelima; Apresiasi pemerintah terhadap setiap jenjang pendidikan yang berhasil menerapkan pendidikan berbasis kecerdasan komprehensif ini (Mayyadah, 2012: 6). Dengan memberikan penghargaan, hingga bantuan beasiswa bagi guru yang ingin meningkatkan kualitas akademiknya.

3. Pesantren Sebagai Model Percontohan

Pesantren yang dimaksud disini adalah pesantren modern, yang tetap mempertahankan sistem salaf dan mengkombinasikannya dengan perkembangan global. Beberapa nilai plus pesantren yang tidak dimiliki pendidikan konvensional, antara lain: Pertama; di pesantren, ilmu-ilmu transedental tetap menjadi prioritas, namun pesantren juga tetap membuka kelas bahasa asing, kelas IPTEK, dan fasilitas lain pendukung kompetensi kognisi. Pesantren Mahasiswa misalnya, memberikan sebuah angin segar baru dalam inovasi pendidikan. Kedua; budaya mondok di asrama, membantu internalisasi nilai-nilai IESAQ ke semua lapisan di lingkup pesantren. Ketiga; di pesantren, keteladanan seorang pendidik adalah sebuah keniscayaan, sehingga membantu internalisasi nilai-nilai IESAQ secara alami kepada seluruh peserta didik. Keempat; pesantren lebih bersifat ekonomis. Kelima; pesantren merupakan lembaga pendidikan tertua di tanah air yang memiliki berbagai karakteristik dan corak kultural khas. Penetapan pesantren sebagai model percontohan pendidikan yang ideal dan mensejajarkannya dengan lembagalembaga pendidikan lain merupakan salah bentuk pelestarian akan warisan budaya Indonesia. Jadi, pendidikan berbasis IESAQ dilakukan dengan cara rekonstruksi kurikulum menjadi kurikulum holistik, optimalisasi nilai ESAQ dalam komunitas pendidikan, dan pesantren sebagai model percontohan.

\section{PENUTUP}

\section{Simpulan}

IESAQ dalam perspektif Islam yaitu kemampuan untuk mengerti, memahami dan berfikir (rasio) menangkap gejala sesuatu, daya menghubungkan, menilai, dan kemampuan memecahkan masalah dengan logika. Kemampunan qalb untuk memahami, mengolah, menampung realita sekelilingnya dan memutuskan sesuatu juga kemampuan pengendalian diri, nafsu dan emosi serta pengetahuan tentang diri sendiri. Dan kemampuan ruh dalam menghayati, merasakan dan menyadari akan eksistensi Tuhan guna mendapatkan pencerahan Ilahiyah dalam nilai atau maknakehidupan yang universal dan transendental. Dan kemampuan serta memiliki keberanian menghadapi risiko akan menuntaskan pekerjaan. Mampu menikmati proses menuju keberhasilan walau mereka tahu bahwa akan banyak rintangan dan kesulitan yang menghadang. Namun, di balik kesulitan itu ia akan 
mendapatkan banyak kemudahan Perkembangan IESAQ dipengaruhi oleh faktor bawaan, kematangan, pembentukan, minat dan kebebasan juga dipengaruhi proses pelatihan dan pendidikan yang kontinu.

$$
\text { Strategi Meningkatkan }
$$

IESAQ: melalui pengalaman kegiatan intelektual, pengalaman terstruktur dan puasa, safar, zikr, kontemplasi, zuhud dan jihad. Atau dengan strategi tathahhur yaitu pembiasaan taat syari'at, muhasabah, mujahadah dan riyadhah al-nafs. Selain itu dengan strategi Mission Statement, character Building, Self Controlling, Strategi Collaboration, Total Action. Aspek/ranah IESAQ: mampu memahami hukum kausalitas, mampu memahami adanya sistem jagad raya, mampu berpikir distinkip, mampu berpikir kritis, terhadap pendapat dan gagasan yang disampaikan orang lain yang tidak mempunyai pijakan kebenaran., mampu mengatur taktik dan strategi perjuangan sehingga tidak terjebak pada strategi lawan dan mampu mengambil pelajaran dari pengalaman, mampu mengendalikan dorongan nafsu, memotivasi diri sendiri, bertahan dalam menghadapi cobaan, tidak melebih-lebihkan kesenangan, mampu mengatur suasana hati, menjaga agar beban stress tidak melumpuhkan kemampuan berpikir, berempati dan berdo'a, tobat, sabar, syukur, harap, takut, zuhud, tawakal dan mahabbah.

Adapun pendidikan berbasis IESAQ dilakukan dengan cara rekonstruksi kurikulum menjadi kurikulum holistik, optimalisasi nilai IESAQ dalam komunitas pendidikan, dan pesantren modern sebagai model percontohan.

\section{DAFTAR PUSTAKA}

Agustian, Ary Ginanjar. (2001). Rahasia Sukses Membangun Kecerdesan Emosi dan Spritual. Jakarta: Arga Wijaya Persada.

, Ary Ginanjar ESQ. (2001). Berdasarkan 6 Rukun Iman dan 5 Rukun Islam. Jakarta: Arga.

Al-Bukhari. (1971). Shahih Bukhari. Bairut: Dar Al-Kutub.

Al-Gazali. ([t.th.]). Ihya Ulumuddin, juz $\quad I V . \quad$ Semarang: Maktabah Usaha Keluarga.

An-Nasa'i. (1348 H). Sunan Nasa'i, bab kam diyat al-kafir, juz 14, Beirut, Lebanon: Dar al-fikr.

As-Suyuthi, Jalaluddin Abdurrahman ibnu Abi Bakar. ([t.th]). AlJami' Al-Shaghir, juz II, Beirut: Darul Fikri,

Aziz, Hamka Abdul. (2011). Pendidikan Karakter Berpusat pada Hati. Jakarta: Al-Mawardi Prima.

Bradley, Rea. (28 Agt-10 Sept 1999). "Anak Humoris, Sehat dan Cerdas EQ-nya." dalam Majalah Ayahbunda, No. 17. 
Chaplin, JP, (1989). Dictionary of Psychology. terj. Kartini Kartono dengan judul Kamus Lengkap Psikologi, Jakarta: Rajawali Press.

Dawud, Abu. ([t.th]). Sunan Abu Daud, juz 4. Beirut. Lebanon: Dar al-Kutub alIlmiah.

Departemen Pendidikan Nasional. (2002). Kamus Besar Bahasa Indonesia. Edisi ketiga Jakarta: Balai Pustaka.

E-mail: $\quad$ aswandi@yahoo.com/21 April 2012. Adversity Quotient dan Pemberdayaan Karyawan.

Ginanjar, Ari. (2002). ESQ. Jakarta: Penerbit Arga.

Goleman, Daniel. (1999). Emotional Intelligence. terj. $\mathrm{T}$. Hermaya Jakarta: Gramedia Pustaka Utama.

Hasanah, Mila. (2007). IEQ dalam Perspektif Psikologi Qur'ani, dalam Jurnal Ittihad. Vol. 5 No. 8 Oktober 2007. Kalimantan: Kopertais Wilayah XI.

Hawwa, Sa'id. (2002). AlMustakhlish fi Tazkiyat alAnfus. terj. Ainur Rafiq Shaleh Tahmid, Jakarta: Rabbani Press.

Jahja, M. Zurkani. (1997). Teologi Islam Ideal Era
Global(Pelbagai
Problem Teologis). Banjarmasin: IAIN Antasari.

Jalaluddin. (1998). Psikologi Agama. Jakarta: PT. Raja Grafindo Persada.

Langgulung, Hasan. (1998). Pendidikan Islam Menghadapi Abad ke-21. Jakarta: Pustaka Al-Husna, 1988.

Levin, Malinda Jo. (1978). Psyichology, A Blographical Approach. New York: Mc Graw-Hill Book Company.

Ludington-Hoe, Susan\&Susan K. Golant. (2001). Membuat Anak Cerdas. Jakarta: Prestasi Pustaka.

Majah, Ibnu. (1404 H). Sunan Ibnu Majah. Jeddah: Syirkah alArabiyah Al-Su'udiyah.

Manzur, Ibn. ([t.th]). Lisan al 'Arab. jilid IV. Kairo: Dar alMa'arif.

Mubarak, Achmad. (2001). Psikologi Qur'ani, Jakarta: Pustaka Firdaus.

Marshall, Zohar-Ian. (2000). SQ; Spiritual Intelligence-The Ultimate Intellence. London: Bloomsbury.

Mayyadah, ([t.th]). Pendidikan Berbasis ESQ, sebuah Solusi Dekadensi Moral Bangsa, 
www.atdikcairo.org/file/ma

kalah-mayyadah.doc

Mubin. (2004). Konsep Kecerdasan Emosional dan Spritual (ESQ) dalam Perspektif Tasawuf Al-Gazali (Telaah Pemikiran Al-Gazali dalam Kitab Ihya 'Ulum Adin), Banjarmasin:Tesis Program Pascasarjana IAIN Antasari.

\section{------. (2005). ESQ dalam Perspektif AlGazali. Banjarmasin: Antasari Press.}

(29 Mei 2010). Pendidikan Islam Berbasis IQ, EQ, SQ. Makalah dalam Seminar Regional "Pendidikan Islam Berbasis IQ, EQ dan SQ, IAIN Antasari.

Mujib. (2001). Abdul dan Jusuf Mudzakir, Nuansa-Nuansa Psikologi Islam, Jakarta: PT. RajaGrafindo Persada.

Mulkhan, Abdul Munir. (1993). Paradigma Intelektual
Muslim. Yogyakarta:

Muslim. (1972). Shahih Muslim. Beirut. Libanon: Dar ihya al-Turas.

Nashori, Fu'ad (ed.). (1994). Membangun Paradigma Psikologi Islam, Yogyakarta: SIPPRESS.

Najati, M. Utsman. 2003. Belajar $E Q$ dan $S Q$ dari Sunnah Nabi, terj. Irfan Sali. Jakarta: Hikmah.

Nggermanto,Agus. (2002). Quantum Quotient (Kecerdasan Quantum), Bandung: Penerbit Nuansa.

Salati, Suriansyah. (2009). Hakikat $I Q, E Q$ dan $S Q$, dalam Perspektif Pendidikan Agama Islam. Banjarmasin: Antasari Press.

Segal, Jeanne. (2001). Meningkatkan Kecerdasan Emosional. terj. Dian Paramesti Bahar, Jakarta: PT. Citra Aksara. 